\title{
Current Molecular Genetic Technologies to Study Hospital Strains
}

DOI: $10.17691 / \mathrm{stm} 2019.11 .4 .15$

Received October 23, 2019

1.V. Belova, PhD, Leading Researcher, Laboratory of Human Microbiome and Means for Its Correction";

A.G. Tochilina, PhD, Senior Researcher, Laboratory of Human Microbiome and Means for Its Correction';

O.V. Kovalishena, DSc, Professor, Head of Department of Epidemiology, Microbiology and Evidence-Based Medicine?;

1.Y. Shirokova, PhD, Head of Laboratory Research, Research Institute of Preventive Medicine, University Clinic²;

E.V. Belyaeva, PhD, Leading Researcher, Laboratory of Microbiology';

L.Y.Poslova, $\mathrm{PhD}$, Senior Lecturer, Department of Epidemiology, Microbiology and Evidence-Based Medicine²;

G.B. Ermolina, PhD, Senior Researcher, Laboratory of Microbiology";

I.V. Solovyeva, DSc, Leading Researcher, Head of Laboratory of Human Microbiome and Means for Its Correction ${ }^{1}$

'Blokhina Scientific Research Institute of Epidemiology and Microbiology of Nizhny Novgorod,

Russian Federal Service for Surveillance on Consumer Rights Protection and Human Wellbeing (Rospotrebnadzor), 71 Malaya Yamskaya St., Nizhny Novgorod, 603950, Russia;

2Privolozhsky Research Medical University, 10/1 Minin and Pozharsky Square, Nizhny Novgorod, 603005, Russia

The aim of the study was to assess the efficiency of a complex of molecular genetic techniques: PCR, RAPD, and MLST using MALDI-TOF mass-spectrometry to study the characteristics of hospital strains.

Materials and Methods. We identified 23 strains of $K$. pneumoniae isolated in a pediatric hospital using MALDI-TOF massspectrometer Autoflex and MALDI Biotyper software (Bruker Daltonics, Germany). Antibiotic sensitivity was analyzed by means of an automatic bacteriological analyzer Phoenix-100 (Becton Dickinson, USA) using chromogenic culture media (HiMedia, India). The search for resistance determinants and molecular typing were performed using PCR, RAPD, and MLST.

Results. All the strains were identified as $K$. pneumoniae ssp. pneumoniae. According to antibiotic sensitivity, three groups were distinguished: group $1(n=15)$ - sensitive strains (wt); group $2(n=7)$ - potential carbapenemase-producers; group $3(n=1)-$ extendedspectrum beta-lactamase producers. No resistance determinants were found in groups 1 and 2; beta-lactamases bla SHV $_{\text {and }}$ bla ${ }_{C T X-M}$ were revealed in group 3 strain. We identified RAPD-type of the strain, a capsule type (K-23), it belonging to the sequence type 17. Strains with this sequence type are rarely isolated in Russia, however, they are known in Europe, USA, and Asian countries, they being associated with lethal human pathologies and a high epidemic potential.

Conclusion. The use of a complex of current techniques to study the phenotypic and genotypic properties of microorganisms enabled to isolate and characterize a hospital strain K. pneumoniae, which is antibiotic-resistant due to the presence of beta-lactamases: bla ${ }_{C T X-M-15}$ and $b_{\text {SHV-11 }}$, and it being dangerous in terms of resistance determinants transmission.

Key words: K. pneumoniae; sequence-type ST-17; antibiotic resistance; MLST; RAPD; PCR; MALDI-TOF spectroscopy.

\section{Introduction}

Klebsiella pneumoniae is a widespread Enterobacteriaceae representative, it occurring in soil, surface waters, on plant leaves, as well as it colonizes mucosa of mammals including humans. In Russia, as worldwide, $K$. pneumoniae is a clinically relevant hospital pathogen causing a wide range of pathologies [1, 2].

Outbreak incidence caused by the microorganism is recorded both in pediatric hospitals, primarily, in neonatal ICU and neonatology, as well as in surgical and orthopedic hospital departments [3-5].

Marked pathogenic potential of $K$. pneumoniae is due to the cell structure features: a lipopolysaccharide capsule, which prevents phagocytosis and macroorganism complement system functioning, and fimbriae of several types providing invasion and biofilm formation. A microorganism produces enterotoxins and a number of enzymes - neuraminidase, deoxyribonuclease, phosphatase and siderophores (enterobactin, aerobactin, etc), which enable the bacterium to uptake iron from host's cells enhancing its pathogenic power [6].

$K$. pneumoniae refer to a group of antibiotic resistant pathogens ESKAPE (Enterococcus faecium, Staphylococcus aureus, Klebsiella pneumoniae, Acinetobacter baumannii, Pseudomonas aeruginosa, and Enterobacter spp.). According to literature, 
most hospital $K$. pneumoniae strains are producers of extended-spectrum beta-lactamase (ESBL) and frequently - carbapenemases located on conjugative plasmids, i.e. the enzymes related to high rate of antibiotic-resistance in the world [7]. The strains oftimes have combined resistance to carbapenems and cephalosporins, and in some cases can require the review of standard schemes of antimicrobial therapy and including alternative antibiotics [8].

The research and monitoring of $K$. pneumoniae strains are key research trends both in Russia, and abroad [9-13]. Recently, one of accurate methods to identify microorganisms is MALDI-TOF mass-spectrometry [14], some foreign researchers suggest using the technique to screen the strains carrying carbapenemase $\operatorname{bla}_{K P C}(K$. pneumoniae carbapenemase $-\mathrm{KPC}$ ), it is recorded in mass-spectrum as a peak of $11.109 \mathrm{Da}$. The peak is associated with protein p019, its gene is a part of transposon Tn4401a, which in $97.8 \%$ cases is represented in KPC-positive $K$. pneumoniae $[15,16]$. The relationship of the leak and the presence of bla is recognized significant in a new software by Bruker Daltonics (Germany) - MALDI Biotyper Subtyping Module [17].

Modern chromogenic media and automatic bacteriological analyzers are used to study the sensitivity of bacteria to antibiotics; PCR-based test systems are used to detect genetic determinants [18, 19]. Currently, the most common determinants of $K$. pneumoniae beta-lactamases in Russia are genes CTX-M, TEM, SHV, OXA-48, and their combinations [2, 13, 20-22].

Pulsed-field gel electrophoresis (PFGE), restriction fragment length polymorphism (RFLP), as well as nucleic acids amplification methods: random amplification of polymorphic DNA (RAPD), and enterobacterial repetitive intergenic consensus (ERIC-PCR) are applied for typing clinically significant strains [21].

For routine monitoring of circulating strains, PFGE and RAPD are used. PFGE is recognized to be a gold standard of epidemiology, however it is rather sophisticated and labor-intensive. Among the disadvantages of RAPD are its availability, ease of use, and a short-term result [23]. The technique is also successfully used for typing clinical strains of K. pneumoniae [24-27].

Multiple loci sequence typing (MLST) based on the analysis of gene sequences enables to conclude about pathogenic potential, assess a clinical role and epidemiological significance of an isolate making it possible to identify a strain sequence-type and its clonal belonging using global databases, and compare an isolate under study with the strains from different parts of the world, and study their relation [13, 28, 29].

The aim of the study was to reveal the features of the hospital strains of $K$. pneumoniae using MALDI-TOF mass-spectrometry and a complex of molecular genetic techniques: PCR, RAPD, and MLST.

\section{Materials and Methods}

We studied 23 strains of $K$. pneumoniae isolated from the biological material of patients suffering from infections related to medical treatment and external environmental objects (wipe-samples from equipment) during epidemic ill-being in a pediatric inpatient department. All samples were taken in August-September 2015.

Strains were identified using a time-of-flight MALDITOF mass-spectrometer Autoflex and a hardware and software system MALDI Biotyper (Bruker Daltonics, Germany). The samples of daily cultures of the test microorganisms were prepared by a direct application method according to a standard protocol provided in a user's manual. Mass-spectra were identified, recorded, processed and analyzed using a hardware and software system MALDI Biotyper.

To reveal the strains producing ESBL and having a decreased sensitivity to carbapenems, we used chromogenic media M1829 HiCrome ESBL Agar Base and M1831 HiCrome KPC Agar Base made by HiMedia (India), cultures were done in three replications.

Antibiotic-sensitivity of strains was determined using an automatic bacteriological analyzer Phoenix-100 (Becton Dickinson, USA) and combined ID/AST-panels. When characterizing microorganisms we used the accepted parameters: "sensitive", "moderately resistant" and "resistant" strains, EUCAST being applied when recording and interpreting the findings [30].

Total DNA for further detection of beta-lactamase genes was isolated using a set DNA-express (Litech, Russia). Bla $a_{T E M}$ and bla PCR with specific primers [31,32], and bla $a_{C T X-M}, b / a_{K P C}$, bla $a_{O X A-48}, b / a_{N D M}, b / a_{I M P}$, and bla $a_{V I M}$ determinant - using commercial Litech test-systems. PCR was performed by a Tertsik amplificatory (DNA-technology, Russia). RAPDtyping was conducted using the primers mentioned in scientific literature [26].

Genome-wide sequencing was performed powered by MiSeq (Illumina, USA), contigs were assembled using a genome assembler SPAdes v. 3.11.1 (Alferov Saint Petersburg National Research Academic University of the Russian Academy of Sciences), and the annotation of obtained contigs - by using software Prokka v. 1.12 [33].

Applying genome-wide sequencing and bioinformatical service available online on the sites of Pasteur Institute (France) - http://bigsdb.pasteur.fr, there were identified gene variants of beta-lactamases and their localization, capsule type of the strain (C-type) and its sequence-type. To identify C-type we analyzed a nucleotide sequence of gene wzi encoding the protein lectin responsible for capsule attachment to the outer cell membrane. The alleles of the gene are strictly associated with a capsule type of strains [34].

MLST was performed according to the scheme based on 7-gene sequence analysis [28]. 


\section{Results}

In the course of the work, all strains were identified as $K$. pneumoniae ssp. pneumoniae, the value of the coefficient of coincidence being 2.1 and more, it indicating perfect species identification. The analysis of the obtained mass-spectra and mass-lists revealed no peak-markers $b / a_{K P C}$ corresponding to the size of 11.109 Da (Figure 1).

The strains studied for ESBL and reduced sensitivity to carbapenems showed the growth of one strain K. pneumoniae 1013 on M1829 HiCrome ESBL Agar Base. On a dense culture medium there were observed large mucous colonies of blue-grey color, which, according to the instruction, are the characteristic for the strains producing ESBL (Figure 2). The analysis using chromogenic media revealed no strains with reduced sensitivity to carbapenems.

Concurrently, we studied the antibiotic sensitivity profiles of all the strains under study using an automatic bacteriological analyzer Phoenix-100. A total of three phenotypic groups were distinguished.
Group 1 involved 15 K. pneumoniae strains sensitive to all antibiotics of cephalosporins and carbapenems, ampicillin resistant, and moderately sensitive to one of "protected" penicillins (piperacillin/tazobactam). The strains included in this group were referred to a wild type - wt (see the Table).

Seven strains, ampicillin resistant, with moderate resistance to imipenem, were referred to group 2 potential producers of carbapenemase.

Group 3 included one strain - K. pneumoniae 1013 characterized by resistance to all antibiotics of cephalosporins series, except for cefoxitin and sulfanilamide (trimethoprim/sulphamethoxazole), i.e. it can be referred to the strains with ESBL.

PCR revealed no resistance determinants in the representatives of groups 1 and 2, and strain K. pneumoniae ssp. pneumoniae 23 was found to have beta-lactamases of two types $-b^{-} a_{S H V}$ and $b / a_{C T X-M}$.

Genotyping of the strain sampling using RAPD enabled to unite the isolates under study according to electrophoretic patterns and antibiotic-resistant phenotype typical for strains (Figure 3 ).

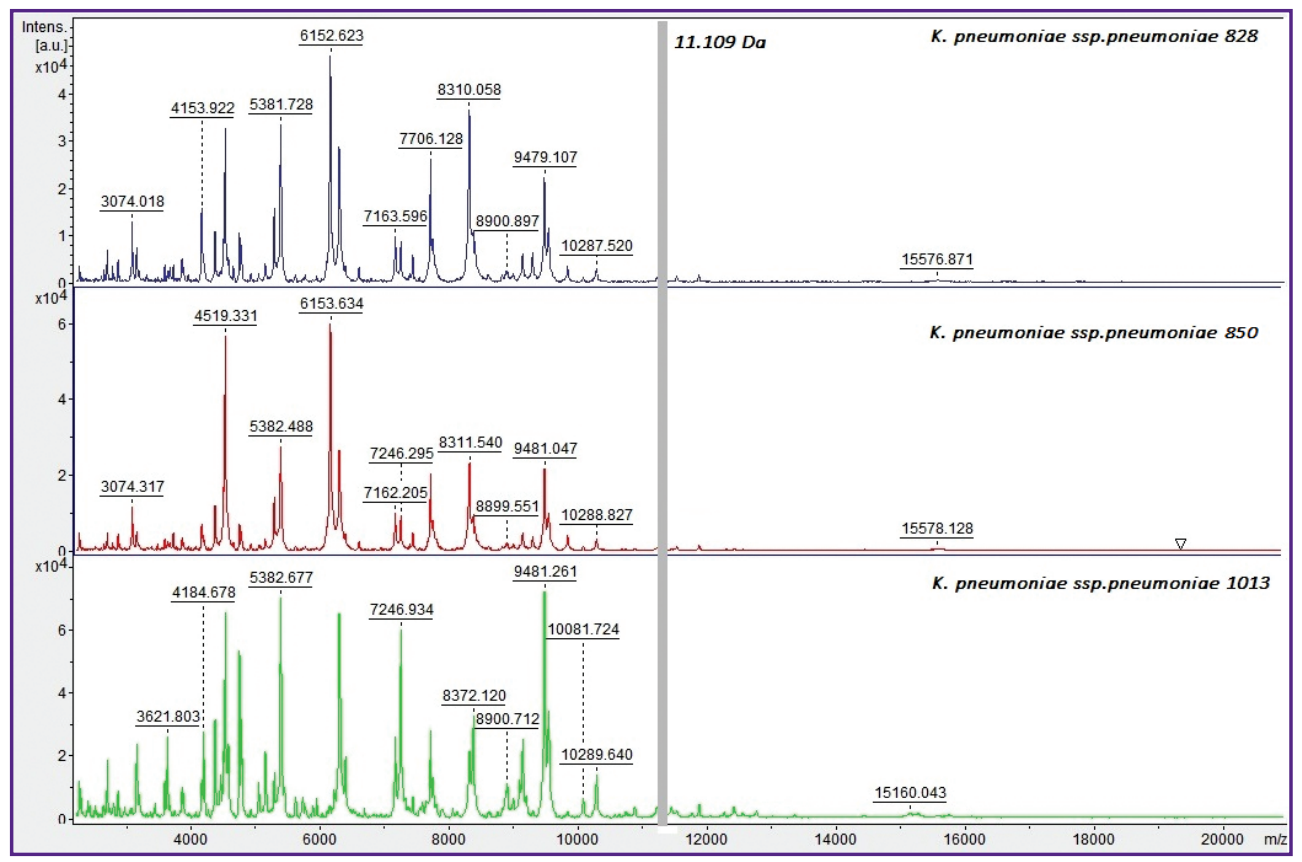

Figure 1. Mass-spectra of $K$. pneumoniae strains under study

$\mathrm{X}$-axis shows ion mass-to-ion charge relation ( $\mathrm{m} / \mathrm{z})$, Y-axis shows signal intensity (Intens.)

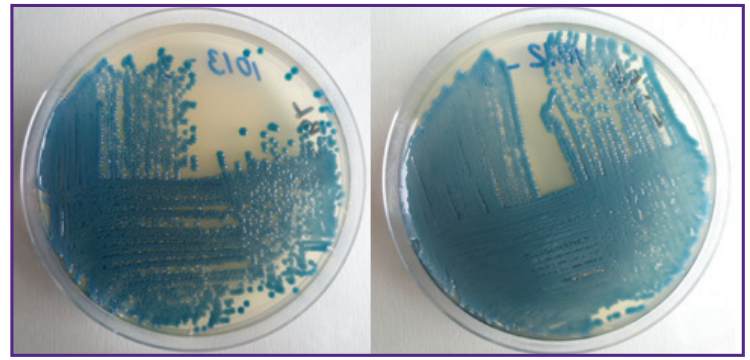

Figure 2. Growth of K. pneumoniae 1013 strain on culture medium HiCrome ESBL Agar Base (M1829; HiMedia, India) 


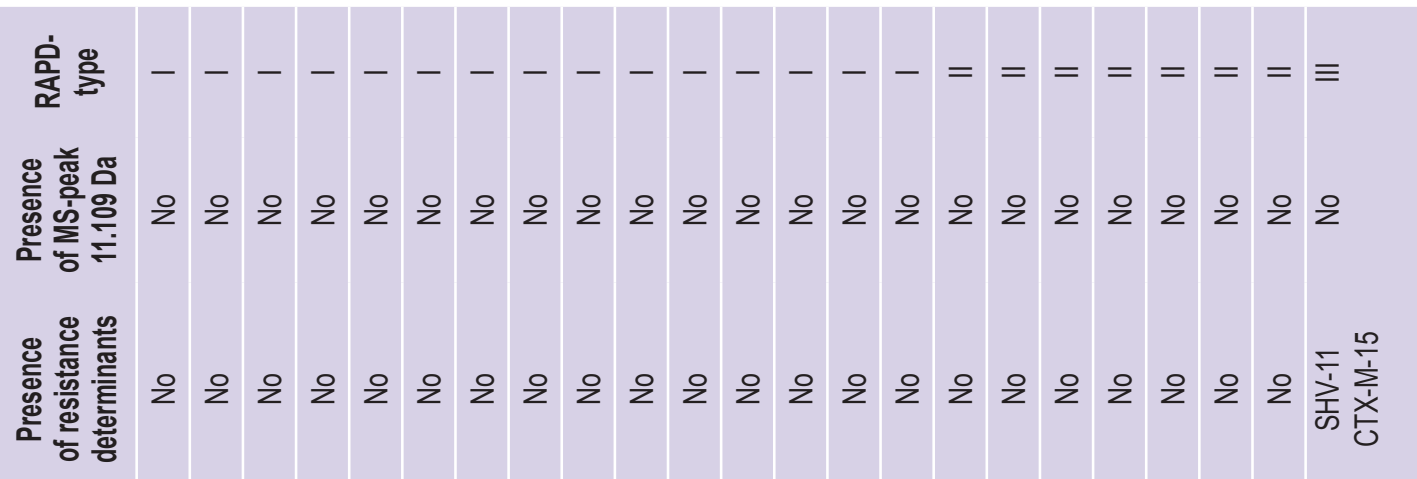

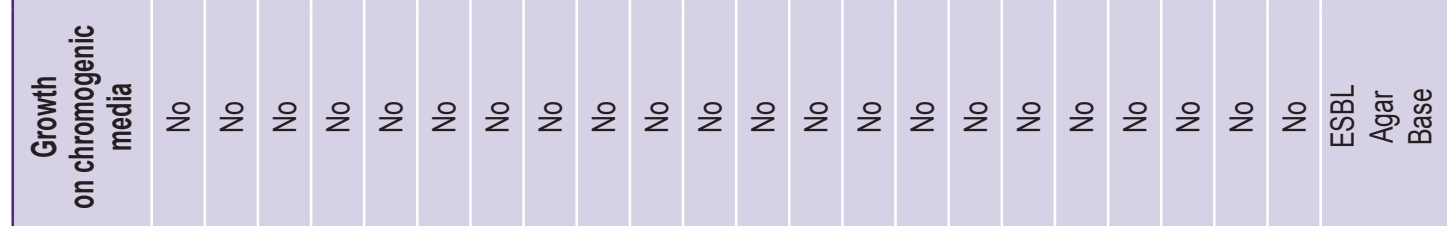

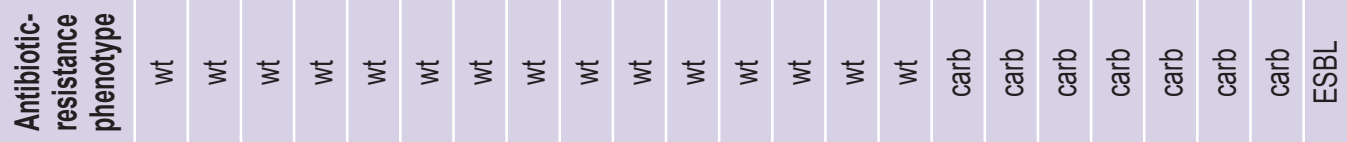

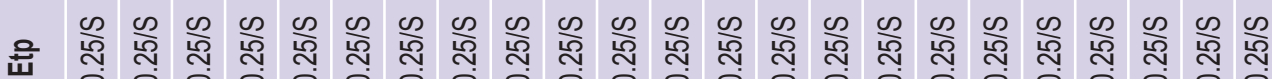

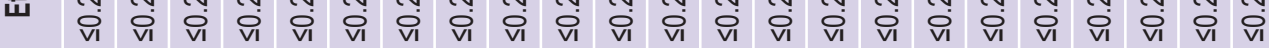





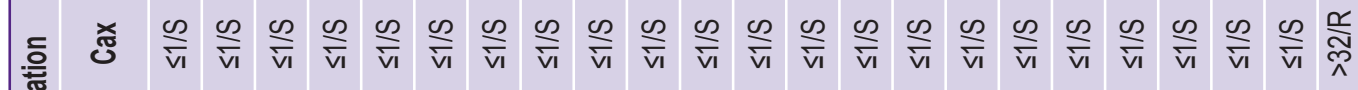

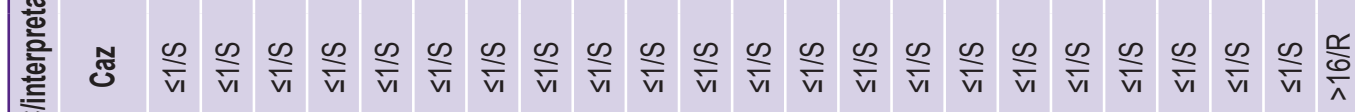

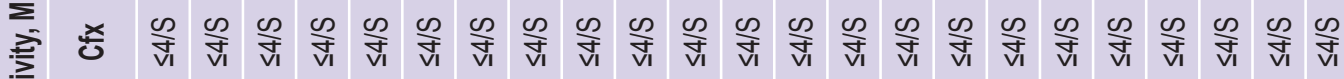

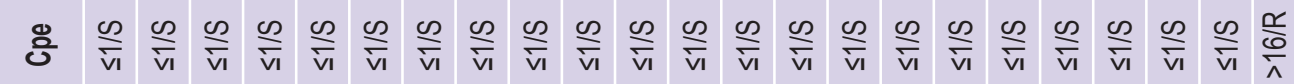

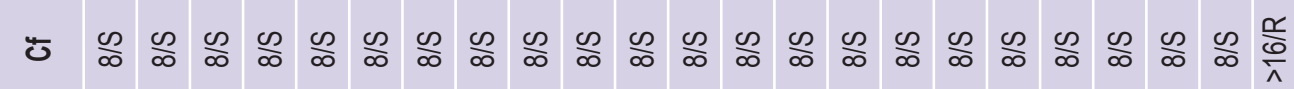

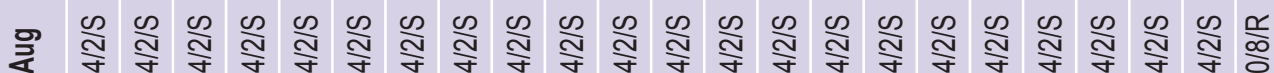

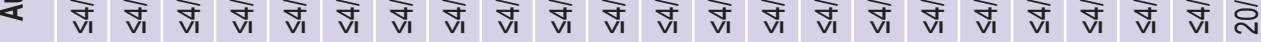

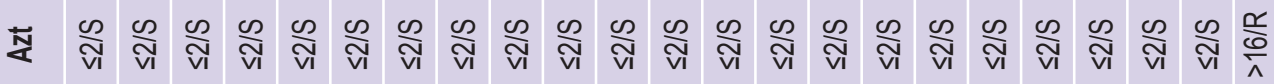

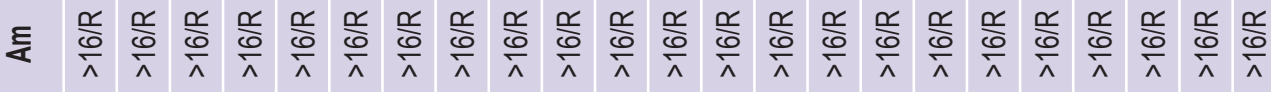

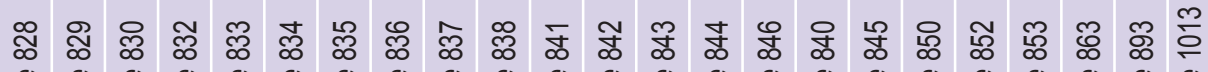




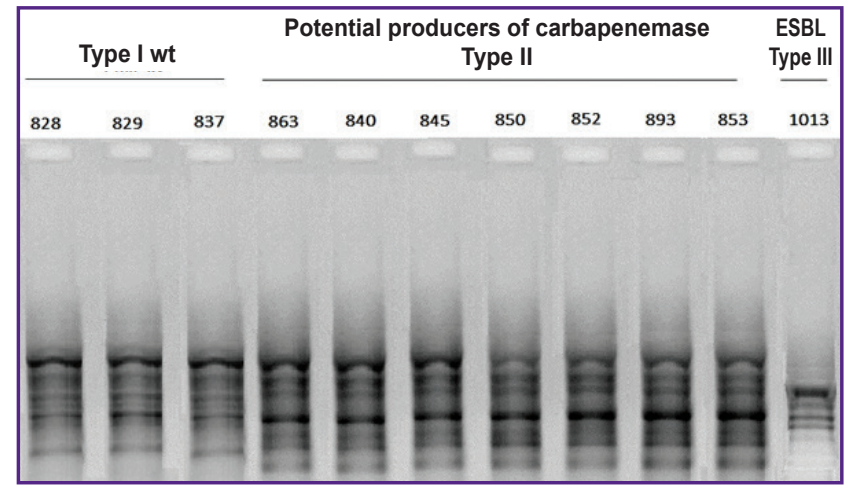

Figure 3. Electrophoregram of RAPD-typing patterns of hospital strains $K$. pneumoniae ssp. pneumoniae

The analysis of genome-wide sequencing of K. pneumoniae ssp. pneumoniae 1013 strain enabled to identify the previously revealed beta-lactamases as $b / a_{S H V-11}$ and $b l a_{C T X-M-15}$; and the first was found to have chromosomal localization, while bla $a_{C T X-M-15}$ was stated to locate on a plasmid; and identify the strain belonging to a capsule type K-23, and perform MLST-analysis. During MLST-analysis of the strain there were identified allelic profiles of 7 genes: glyceraldehyde-3-phosphate dehydrogenase (gapA), translation initiation factor IF-2 (infB), malate dehydrogenase $(m d h)$, glucose6-phosphate isomerase (pgi), phosphorin $\mathrm{E}$ (phoE), beta-subunits of RNA polymerase (rpoB), periplasmatic energy transductor (ton $B)$ - and the strain was found to belong to sequence-type 17 .

Thus, a hospital strain with a wide antibioticresistance spectrum was identified as $K$. pneumoniae ssp. pneumoniae 1013 ST-17 ${ }^{\mathrm{K}-23}$.

\section{Discussion}

Mass-spectra analysis of all the strains under study enabled to identify them as $K$. pneumoniae ssp. pneumoniae, and revealed no peak related to $b / a_{K P C}$ presence. The lack of carbapenemase activity and this determinant in the strains were later proved by the findings obtained using chromogenic media and PCR.

The study of antibiotic-resistance profiles showed all $K$. pneumoniae ssp. pneumoniae to be ampicillinresistant, that can be due to nature resistance of the microorganism $[8,35]$. Most strains show no resistance to the antibiotics of other groups, and they do not carry corresponding determinant in their genome. Genomes of group 2 strains exhibiting intermediate resistance to carbapenems (imipenem) were also found to have no resistance determinants. It is evident that in this case resistance can result from other mechanisms, for instance, molecular efflux.

Strain K. pneumoniae ssp. pneumoniae 1013, resistant to cephalosporins and phenotypically characterized as ESBL, carries in its genome $b l_{S H V-11}$ and bla ${ }_{C T X-M-15}$ determinants. According to Bush classification [36], both determinants refer to serine beta-lactamases of $A$ class, 2be group. Their presence causes the strain resistance to protected penicillins (amoxiclav), cephalosporins of generations III, IV, and monobactams (aztreonam).

Scientific literature demonstrates $b / a_{C T X-M-15}$ gene to be frequently associated with plasmids of an incompatibility group IncF, IncL/M and IncA/C and a mobile genetic element ISEcp1 [37]. It results in active horizontal gene transfer in population and its spread. Gene bla CTX-M-15 $_{\text {of }}$ the strain under study also has plasmid location and is dangerous in transmissible transfer. What stands out is the fact that the strain under study lacks type TEM-1 beta-lactamases, which are usually included in a complex with bla $a_{S H V-11}$ and bla $_{C T X-M-15}[20]$.

In the course of the study there was demonstrated the capability to use RAPD when studying hospital strains. In this situation there were isolated three RAPDtypes combining the cultures with similar phenotypes. Since scientific literature reports the data suggesting that the strains belonging to different RAPD types have different sequence-types [26], we can say that in this case in the hospital there are three epidemic clones of K. pneumoniae ssp. pneumoniae circulating, one of them has ESBL complex and is dangerous in terms of their transmissible spread. It enabled to study in detail the characteristics of the strain using genome-wide sequence.

A capsule type of $K$. pneumoniae ssp. pneumoniae 1013 - K-23 identified in the course of the present study is non-characteristic for virulent strains and the strains with a hypermucoid phenotype [1]. However, MLST-analysis showed that the strain belonged to sequence type 17 , which is associated with a number of infectious human pathologies: bacteriemia, urinary tract infections, pneumonia, sepsis. The isolation of the strain from patients with infections related to the delivery of health care in an adverse epidemiological situation in hospital can be considered epidemiologically as an unfavorable prognostic sign. The database of Pasteur Institute (Institut Pasteur MLST and whole genome MLST databases, http://bigsdb.pasteur.fr/klebsiella/ klebsiella.html) on 25.07.2018 had the information on 25 isolates of K. pneumoniae ST-17 isolated in Europe, USA, and Asian countries, associated with severe and lethal human pathologies, and having ESBL complex. $K$. pneumoniae with this sequence type rarely occurs in Russia. According to Pasteur Institute database, K. pneumoniae ST-17 strain was isolated once in Moscow from the blood of the patient with sepsis, and registered in the base in 2015.

\section{Conclusion}

The use of current technologies to study the phenotypic and genotypic properties of $K$. pneumoniae 
strains enabled both: to isolate and thoroughly characterize the hospital strain with antibiotic-resistance due to the presence of beta-lactamases: bla $a_{C T X-15}$ and bla $_{S H V-11}$; it poses danger in terms of transmissible spread of resistance determinants, and causes the occurrence of an adverse epidemiological situation by the infections related to health care delivery.

Study funding. The study was funded by the authors.

Conflicts of interest. The authors have no conflicts of interest related to the present study.

\section{References}

1. Lev A.I., Astashkin E.I., Kislichkina A.A., Solovieva E.V., Kombarova T.I., Korobova O.V., Ershova O.N., Alexandrova I.A., Malikov V.E., Bogun A.G., Borzilov A.I., Volozhantsev N.V., Svetoch E.A., Fursova N.K. Comparative analysis of Klebsiella pneumoniae strains isolated in 20122016 that differ by antibiotic resistance genes and virulence genes profiles. Pathog Glob Health 2018; 112(3): 142-151, https://doi.org/10.1080/20477724.2018.1460949.

2. Bisekenova A.L., Ramazanova B.A., Musayeva A.A., Nurmoldin Sh.M., Alibaeva Zh.S., Ugushova Sh.E. Antibiotic resistance of strains of Enterobacteriaceae isolated from patients in multidisciplinary hospitals. Vestnik Kazakhskogo Natsional'nogo meditsinskogo universiteta 2016; 4: 50-54.

3. Edelstein M.V., Zhuravlev V.S., Shek E.A. Prevalence of carbapenemases among the nosocomial strains of Enterobacteriaceae in Russia. Izvestiya Saratovskogo universiteta. Novaya seriya. Seriya: Khimiya. Biologiya. Ekologiya 2017; 17(1): 36-41.

4. Angeletti S., Dicuonzo G., Lo Presti A., Cella E., Crea F., Avola A., Vitali M.A., Fagioni M., De Florio L. MALDITOF mass spectrometry and $b a_{k p c}$ gene phylogenetic analysis of an outbreak of carbapenem-resistant K. pneumoniae strains. New Microbiol 2015; 38(4): 541-550.

5. Shipitsyna I.V., Rozova L.V. Evaluation of pathogenic potential of Klebsiella pneumoniae strains isolated from the wounds of patients with chronic osteomyelitis. Uspekhi sovremennogo estestvoznaniya 2015; 4: 93-96.

6. Piperaki E.T., Syrogiannopoulos G.A., Tzouvelekis L.S., Daikos G.L. Klebsiella pneumoniae: virulence, biofilm and antimicrobial resistance. Pediatr Infect Dis J 2017; 36(10): 1002-1005, https://doi.org/10.1097/inf.0000000000001675.

7. Sukhorukova M.V., Edelstein M.V., Skleenova E.Yu., Ivanchik N.V., Timokhova A.V., Dekhnich A.V., Kozlov R.S., Popov D.A., Astanina M.A., Zhdanova O.A., Bolysheva G.S., Novikova R.I., Valiullina I.R., Kokareva T.S., Chastoedova A.N., Rog A.A., Polikarpova S.V., Gordinskaya N.A., Nekaeva E.S., Abramova N.V., Domanskaya O.V., Zemlyanskaya O.A., Goryunova L.A., Skal'skiy S.V., Elokhina E.V., Popova L.D., Bozhkova S.A., Gomon Yu.M., Krechikova O.I., Mishchenko V.M., Rachina S.A., Strezh Yu.A., Gudkova L.V., Kolosova I.P., Vunukaynen T.M., Ortenberg E.A., Khokhlyavina R.M., Portnyagina U.S., Shamaeva S.Kh., Matveev A.S., Palyutin Sh.Kh., Vlasova A.V., Ershova M.G., Lebedeva M.S., Feoktistova L.V., Gordeeva S.A., Dolinina V.V., Chernyavskaya Yu.L., Bagin V.A., Rozanova S.M., Perevalova E.Yu. Antimicrobial resistance of nosocomial Enterobacteriaceae isolates in Russia: results of national multicenter surveillance study "MARATHON" 2011-2012.
Klinicheskaya mikrobiologiya i antimikrobnaya khimioterapiya 2014; 16(4): 254-265.

8. Kryzhanovskaya O.A., Lazareva A.V., Alyabieva N.M., Tepaev R.F., Karaseva O.V., Chebotar I.V., Mayanskiy N.A. Antibiotic resistance and its molecular mechanisms in carbapenem-nonsusceptible Klebsiella pneumoniae isolated in pediatric ICUs in Moscow. Antibiotiki i khimioterapiya 2016; 61(7-8): 22-26.

9. Dubodelov D.V., Lubasovskaya L.A., Shubina E.S., Mukosey I.S., Korostin D.O., Kochetkova T.O., Bogacheva N.A., Bistritskiy A.A., Gordeev A.B., Trofimov D.Y., Priputnevich T.V., Zubkov V.V. Genetic determinants of resistance of hospital-associated strains of Klebsiella pneumoniae to $\beta$-lactam antibiotics isolated in neonates. Russian Journal of Genetics 2016; 52(9): 993-998, https://doi. org/10.1134/s1022795416090040.

10. Tapalskiy D.V., Petrenyov D.R. Prevalence of carbapenemase-producing Klebsiella pneumoniae isolates in Belarus and their competitive ability. Klinicheskaya mikrobiologiya i antimikrobnaya khimioterapiya 2017; 19(2): 139-144.

11. Gu D., Dong N., Zheng Z., Lin D., Huang M., Wang L., Chan E.W., Shu L., Yu J., Zhang R., Chen S. A fatal outbreak of ST11 carbapenem-resistant hypervirulent Klebsiella pneumoniae in a Chinese hospital: a molecular epidemiological study. Lancet Infect Dis 2018; 18(1): 37-46, https://doi. org/10.1016/s1473-3099(17)30489-9.

12. Zheng X., Wang J.F., Xu W.L., Xu J., Hu J. Clinical and molecular characteristics, risk factors and outcomes of Carbapenem-resistant Klebsiella pneumoniae bloodstream infections in the intensive care unit. Antimicrob Resist Infect Control 2017; 6: 102, https://doi.org/10.1186/s13756-0170256-2.

13. Lazareva I.V., Ageevets V.A., Ershova T.A., Zueva L.P., Goncharov A.E., Darina M.G., Svetlichnaya Yu.S., Uskov A.N., Sidorenko S.V. Prevalence and antibiotic resistance of carbapenemase-producing gram-negative bacteria in Saint Petersburg and some other regions of the Russian Federation. Antibiotiki i khimioterapiya 2016; 61(11-12): 28-38.

14. Berrazeg M., Diene S.M., Drissi M., Kempf M., Richet H., Landraud L., Rolain J.M. Biotyping of multidrugresistant Klebsiella pneumoniae clinical isolates from France and Algeria using MALDI-TOF MS. PLoS One 2013; 8(4): e61428, https://doi.org/10.1371/journal.pone.0061428.

15. Lau A.F., Wang H., Weingarten R.A., Drake S.K., Suffredini A.F., Garfield M.K., Chen Y., Gucek M., Youn J.H., Stock F., Tso H., DeLeo J., Cimino J.J., Frank K.M., Dekker J.P. A rapid matrix-assisted laser desorption ionization-time of flight mass spectrometry-based method for single-plasmid tracking in an outbreak of carbapenem-resistant Enterobacteriaceae. J Clin Microbiol 2014; 52(8): 2804-2812, https://doi. org/10.1128/jcm.00694-14.

16. Gaibani P., Galea A., Fagioni M., Ambretti S., Sambri V., Landini M.P. Evaluation of matrix-assisted laser desorption ionization-time of flight mass spectrometry for identification of KPC-producing Klebsiella pneumoniae. J Clin Microbiol 2016; 54(10): 2609-2613, https://doi.org/10.1128/jcm.01242-16.

17. Gaibani P., Ambretti S., Tamburini M.V., Vecchio Nepita E., Re M.C. Clinical application of Bruker Biotyper MALDI-TOF/MS system for real-time identification of KPC production in Klebsiella pneumoniae clinical isolates. J Glob Antimicrob Resist 2018; 12: 169-170, https://doi. org/10.1016/j.jgar.2018.01.016. 
18. Tapalski D.V., Osipov V.A., Zhavoronok S.V. Carbapenemases of gram-negative pathogens: spread and methods of detection. Meditsinskiy zhurnal 2012; 2(40): 10-15.

19. Afzali H., Firoozeh F., Amiri A., Moniri R., Zibaei M. Characterization of CTX-M-type extend-spectrum $\beta$-lactamase producing Klebsiella spp. in Kashan, Iran. Jundishapur J Microbiol 2015; 8(10): e27967, https://doi.org/10.5812/ jjm.27967.

20. Alekseeva A.E., Brusnigina N.F., Solntsev L.A., Gordinskaya N.A. The molecular typing of clinical isolates klebsiella pneumoniae producing beta-lactamases of extended specter of action. Klinicheskaya laboratornaya diagnostika 2017; 62(11): 699-704.

21. Korobova A.G. Monitoring enterobakteriy s produktsiey beta-laktamaz rasshirennogo spektra, vydelennykh $u$ bol'nykh gemoblastozami pri khimioterapii. Dis. ... kand med nauk [Monitoring of enterobacteria with the production of extended-spectrum beta-lactamases isolated in patients with hemoblastosis during chemotherapy. PhD Dissertation]. Moscow; 2018.

22. Ilyina V.N., Subbotovskaya A.I., Kozyreva V.S., Sergeevitchev D.S., Shilova A.N. Characteristics of Enterobacteriaceae strains producing CTX-M type ESBL in a Cardiac Surgery Hospital. Klinicheskaya mikrobiologiya $i$ antimikrobnaya khimioterapiya 2013; 15(4): 309-314.

23. Shaginyan I.A. Role and significance of molecular methods in epidemiological analysis of nosocomial infections. Klinicheskaya mikrobiologiya $i$ antimikrobnaya khimioterapiya 2000; 2(3): 82-95.

24. Astashkin E.I., Lev A.I., Novikova T.S., Kartsev N.N., Fedyukina G.N., Ershova M.G., Poletaeva E.D., Fursova N.K., Shepelin A.P. Characterization of the antibiotic-resistant clinical isolates of Klebsiella pneumoniae isolated in Yaroslavl in 2016-2017. Bakteriologiya 2017; 2(3): 45.

25. Deschaght P., Van Simaey L., Decat E., Van Mechelen E., Brisse S., Vaneechoutte M. Rapid genotyping of Achromobacter xylosoxidans, Acinetobacter baumannii, Klebsiella pneumoniae, Pseudomonas aeruginosa and Stenotrophomonas maltophilia isolates using melting curve analysis of RAPD-generated DNA fragments (McRAPD). Res Microbiol 2011; 162(4): 386-392, https://doi.org/10.1016/j. resmic.2011.02.002.

26. Sachse S., Bresan S., Erhard M., Edel B., Pfister W., Saupe A., Rödel J. Comparison of multilocus sequence typing, RAPD, and MALDI-TOF mass spectrometry for typing of $\beta$-lactam-resistant Klebsiella pneumoniae strains. Diagn Microbiol Infect Dis 2014; 80(4): 267-271, https://doi. org/10.1016/j.diagmicrobio.2014.09.005.

27. Molekulyarno-epidemiologicheskiy monitoring $v$ sisteme epidemiologicheskogo nadzora za infektsiyami, svyazannymi s okazaniem meditsinskoy pomoshchi. Federal'nye klinicheskie rekomendatsii [Molecular epidemiological monitoring in the system of epidemiological surveillance of infections associated with the provision of medical care. Federal clinical guidelines]. Moscow; 2014.

28. Guo C., Yang X., Wu Y., Yang H., Han Y., Yang R., Hu L., Cui Y., Zhou D. MLST-based inference of genetic diversity and population structure of clinical Klebsiella pneumoniae, China. Sci Rep 2015; 5: 7612, https://doi.org/10.1038/srep07612.

29. Diancourt L., Passet V., Verhoef J., Grimont P.A., Brisse S. Multilocus sequence typing of Klebsiella pneumoniae nosocomial isolates. J Clin Microbiol 2005; 43(8): 4178-4182, https://doi.org/10.1128/jcm.43.8.4178-4182.2005.

30. EUCAST guidelines for detection of resistance mechanisms and specific resistances of clinical and/or epidemiological importance. Version 1.0, 2013. URL: http:// www.eucast.org/fileadmin/src/media/PDFs/EUCAST_files/ Resistance_mechanisms/EUCAST_detection_of_resistance_ mechanisms_v1.0_20131211.pdf.

31. Ikryannikova L.N., Shitikov E.A., Zhivankova D.G., Il'ina E.N., Edelstein M.V., Govorun V.M. A MALDI TOF MSbased minisequencing method for rapid detection of TEMtype extended-spectrum beta-lactamases in clinical strains of Enterobacteriaceae. J Microbiol Methods 2008; 75(3): 385391, https://doi.org/10.1016/j.mimet.2008.07.005.

32. Eftekhar F., Naseh Z. Extended-spectrum $\beta$-lactamase and carbapenemase production among burn and non-burn clinical isolates of Klebsiella pneumoniae. Iran J Microbiol 2015; 7(3): 144-149.

33. Seemann T. Prokka: rapid prokaryotic genome annotation. Bioinformatics 2014; 30(14): 2068-2069, https:// doi.org/10.1093/bioinformatics/btu153.

34. Brisse S., Passet V., Haugaard A.B., Babosan A., Kassis-Chikhani N., Struve C., Decré D. wzi Gene sequencing, a rapid method for determination of capsular type for Klebsiella strains. J Clin Microbiol 2013; 51(12): 4073-4078, https://doi. org/10.1128/jcm.01924-13.

35. Kozlova N.S., Barantsevich N.E., Barantsevich E.P., Goik V.G. Resistance of Klebsiella of various origin to antibiotics. Infektsiya i immunitet 2016; 6(3): 48.

36. Bush K., Jacoby G.A. Updated functional classification of beta-lactamases. Antimicrob Agents Chemother 2010; 54(3): 969-976, https://doi.org/10.1128/aac.01009-09.

37. Fursova N.K., Pryamchuk S.D., Abaev I.V., Kovalev Yu.N., Shishkova N.A., Pecherskikh E.I., Korobova O.V., Astashkin E.I., Pachkunov D.M., Svetoch E.A.,

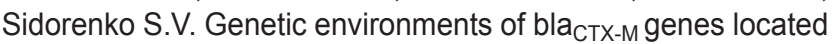
on conjugative plasmids of Enterobacteriaceae nosocomial isolates collected in Russia within 2003-2007. Antibiotiki $i$ khimioterapiya 2010; 55(11-12): 3-10. 